\title{
Regulatory Implications of Cumulative Risk for Perchlorate as an Iodide Uptake Inhibitor
}

\author{
Douglas Crawford-Brown \\ Cambridge Centre for Climate Change Mitigation Research, University of Cambridge, Cambridge, UK \\ Email: djc77@cam.ac.uk
}

Received 30 June 2015; accepted 24 July 2015; published 28 July 2015

Copyright (C) 2015 by author and Scientific Research Publishing Inc.

This work is licensed under the Creative Commons Attribution International License (CC BY).

http://creativecommons.org/licenses/by/4.0/

(c) (1) 0 pen Access

\begin{abstract}
This research applies aggregate and cumulative risk assessment considerations to intakes of compounds acting through the sodium-iodide symporter mechanism to produce iodide uptake inhibition into the thyroid. Four approaches to setting regulatory limits considered here based on NOELS/LOELs yield the following estimates of the safe levels of perchlorate in water (when perchlorate in water is the sole intake) or total goitrogens (PEC) acting through the same mechanism: 1) Approach 1: $18 \mu \mathrm{g} / \mathrm{L} ; 2)$ Approach 2: $400 \mu \mathrm{g} / \mathrm{L} \mathrm{(50 \%} \mathrm{required} \mathrm{inhibition)} \mathrm{or} 38 \mu \mathrm{g} / \mathrm{L}$ (5\% required inhibition); 3) Approach 3: $338 \mu \mathrm{g} / \mathrm{L}$ (without serum half-life correction) or $573 \mu \mathrm{g} / \mathrm{L}$ (with serum half-life correction); 4) Approach 4: $737 \mu \mathrm{g} / \mathrm{L}$ (without serum half-life correction) or 973 $\mu \mathrm{g} / \mathrm{L}$ (with serum half-life correction) for $50 \%$ required inhibition; $375 \mu \mathrm{g} / \mathrm{L}$ (without half-life) or $735 \mu \mathrm{g} / \mathrm{L}$ (with half-life) for $5 \%$ required inhibition. Where water is not the sole route of exposure and perchlorate is not the sole goitrogen acting through the sodium-iodide symporter mechanism, the results of Approaches 3 and 4 can be applied to mixtures of compounds that produce these values as PECs. Results of the analysis suggest that compound-by-compound regulatory limits may be better dealt with through a change to risk-based management strategies that are built around the concept of focusing limited regulatory resources on the main contributors to risks induced by the mechanism considered here.
\end{abstract}

\section{Keywords}

Cumulative Risk, Aggregate Risk, Goitrogens, Perchlorate, Regulatory Rationality

\section{Introduction}

Regulatory decisions must eventually consider how to treat cases of intakes of contaminants through multiple 
pathways and to a mixture of contaminants. The issue arises because the first step in establishing a safe level of exposure to a contaminant has historically been to consider it as a single contaminant (e.g., perchlorate) in a single medium (e.g., water), and then to ask: What is the highest level of exposure to that contaminant in that medium that would, by itself, produce an acceptable level of risk?

Regulatory limits have built-in margins of safety, introduced in the form of uncertainty factors, upper confidence bounds on risk coefficients, maximally plausible scenarios of exposure, etc. The assumption has been that an individual might be exposed to several contaminants via several pathways, but that the overall risk (as discussed in Crawford-Brown and Crawford-Brown [1] although the concept has been in the regulatory community for decades) would still be acceptable due to the presence of the margins of safety.

With the environmental justice movement in the US [2], it was recognized that there were populations exposed to dozens of contaminants, each at levels deemed safe individually, but which together would cause the aggregate risk to be unacceptable, especially in cases where cumulative risk was also considered. The concept of Relative Source Contribution (RSC) was introduced several decades ago in part to deal with the issue of aggregate risk, which quantified the percentage of exposure through any single route, and adjusted the regulatory limit on that single route accordingly. The challenge faced by regulators under these conditions was that there was an understandable desire to have limits on exposure that applied nationally and would be protective of public health even at the extremes where a single individual was exposed at the regulatory limit in each of several environmental media. Otherwise, limits on exposure in any one medium (such as water) might need to differ in different geographic regions and for different individuals due to differences in the contributions of other exposure routes. To do so would appear to raise many of the issues that were found in environmental justice of unequal treatments under the law.

It was recognized that the approach of using RSCs as a way of dealing with aggregate risk was infeasible for cumulative risk because there were too many combinations of contaminants to which individuals in a population might be exposed. To deal with this, the regulatory community first introduced the concept of Hazard Index (HI), which was equal to the sum of the Hazard Quotients (HQ) across all applicable contaminants with the same mode and/or mechanism of action (hereafter, "mechanism"). The HQ is the ratio of the actual ADRI (average daily rate of intake) for an individual, expressed in units of the Reference Dose (RfD, in for example mg/kg-day) divided by the RfD itself. The regulatory reasoning was that individuals should not have a total exposure by all routes and to all contaminants with the same mechanism that produced an HI above 1.

This paper considers different interpretations of the underlying data on perchlorate and other goitrogens that act through the sodium-iodide symporter mechanism in the case of the Greer et al. [3] study using the concepts of cumulative (firstly) and aggregate (secondly) risk, leading to a range of estimates of the safe level of exposure to perchlorate in water and/or total intake of three selected compounds acting at least in part through this mechanism; "safe" here means reasonable confidence that the exposure limit avoids an unacceptably large risk in a substantial fraction of the population, including consideration of the precautionary principle [4] [5]. The analysis considers only the action of compounds through the sodium-iodide symporter mechanism, as this has been the interpretation of the original Greer et al. [3] results in proposing potential regulatory limits on perchlorate exposure.

Before proceeding with the analysis, several caveats must be mentioned to isolate what this analysis is and is not. Significant scientific advances have been made in both physiologically based pharmacokinetic and biologically based dose-response models, in addition to probabilistic risk assessment (for example, the extensive discussions and analyses that took place in the USEPA NexGen program; see the descriptions of the program at: www.epa.gov/riskassessment/nexgen). Some of these advances are recommended for the case of perchlorate specifically in a recent EPA White Paper [6], albeit not applied to the case of cumulative risk in that particular paper. These advances allow for greater use of biological data to resolve issues such as aggregate and cumulative risk, and have been called for by scientific advisory bodies. They have also been applied in some cases to develop the Dose Modifying Factors as a subset of Uncertainty Factors, which is at least a partial application of their methodologies. When those advances have been mainstreamed into risk-based policy decisions, analyses such as the one presented here will be supplanted by these advanced modes of analysis. The present analysis considers an incremental advance in regulatory decisions on perchlorate in the interim, providing a sensitivity analysis of potential regulatory limits on perchlorate exposure when the study of Greer et al. [3] is retained as the primary data set on effects, and where the mechanism of action is the sodium-iodide symporter mechanism, and where PBPK and BBDR models are not applied to the estimates of cumulative risk. 


\section{The Methodology of Protecting Public Health through Regulatory Limits on Exposure}

In the following calculations for this study, the concepts of HQ and HI are retained as fundamental to traditional regulatory practice, including risk management decisions. If there are two compounds to which a population is exposed simultaneously, their individual ADRI values will be shown as ADRI1 and ARDI2. Their respective RfD values will be RfD1 and RfD2. Their HQ values are then HQ1 = ADRI1/RfD1 and HQ2 = ADRI2/RfD2. The HI value is then:

$$
\mathrm{HI}=\mathrm{HQ} 1+\mathrm{HQ} 2=\mathrm{ADRI} 1 / \mathrm{RfD} 1+\mathrm{ADRI} 2 / \mathrm{RfD} 2
$$

Assuming the two compounds act by the same mechanism (technically a requirement for applying the concept of $\mathrm{HI}$ ), the equation above reduces to:

$$
\mathrm{HI}=(\mathrm{ADRI} 1+\mathrm{ADRI}) / \mathrm{RfD}
$$

where there is now no subscript on RfD since the RfD value is the same for all compounds acting through this shared mechanism, assuming ADRI has been calculated for each compound using a Toxicity Equivalency Factor (in perchlorate risk assessment, the TEF is replaced by the Perchlorate Equivalent Concentration or PEC). While additivity has not been fully explored for goitrogens acting through the sodium-iodide symporter mechanism, it has been shown to hold for Thyroid Disrupting Chemicals more broadly [7] and so is a reasonable assumption here. Following the caveats at the end of Section 1, this assumption eventually will be replaced by more biologically based dose-response models as those come to play a more prominent role in aggregate and cumulative risk assessment for classes of compounds acting through the mechanism of perchlorate effects.

A key consideration of this issue in the discussion of Section 3 is that this same summation of exposures must be carried through the analysis of all primary data used to calculate the RfD (often requiring re-analysis of those data).

\section{Application to Perchlorate and Goitrogens Acting through the Sodium-Iodide Symporter Mechanism}

The debate over regulation of perchlorate revolves around the following issues:

- The underlying study by Greer et al. [3] used iodide uptake inhibition as the measure of effect. Iodide uptake inhibition, however, is not an adverse effect in and of itself; it is a precursor to an adverse effect (changes in hormonal levels leading in turn to developmental and metabolic alterations). This allows establishment of a NOEL but not a NOAEL. From this point forward, the paper refers to the NOEL rather than the NOAEL. In addition, more recent research on modeling of serum levels suggests that iodide uptake inhibition may not be the only mechanism through which perchlorate induces adverse effects [8]. If that is demonstrated to be the case, the adoption of the PEC values later in the current paper may need to be adjusted. In the interim, this paper considers only actions through the sodium-iodide symporter mechanism.

- Perchlorate is a member of the class of goitrogens that exert at least part of their effect through competitive inhibition of iodide uptake into the thyroid by the sodium-iodide symporter, which includes a wide range of compounds such as nitrates, perchlorates, chlorates and thiocyanates [9].

- The study of Greer et al. [3] uses a bolus dose regime for the study subjects. Application of such results to the case of environmental exposures at much lower levels ignores the significant body of scientific evidence concerning the dose rate effect [10]. This issue is significant here because the study subjects in the study of Greer et al. [3] are administered perchlorate concentrations of at least $180 \mathrm{ppb}$, which is a factor of 18 (180 ppb divided by a typical maximum concentration of $10 \mathrm{ppb}$ in water outside hotspots) to 1800 (180 ppb divided by a typical average concentration of $0.1 \mathrm{ppb}$ in water outside hotspots) higher than environmental levels found in the large majority of water systems. In these cases, the rapid upswing of serum concentration would be large compared to the more sustained concentrations of recirculating perchlorate as well as the external and endogenous contributions of the other compounds considered later in this paper.

- The individuals in the Greer et al. [3] study were exposed to each of the three compounds considered in the current study simultaneously through their diet because there was no control on these additional compounds and routes of exposure; hence the NOEL and the RfD as developed using only the administered doses in the study of Greer et al. [3] understates the magnitude of the exposures to goitrogens acting through the sodiumiodide symporter mechanism which presumably leads to this NOEL or RfD. 
- If a RSC value is then applied to the RfD, this is "double counting” the treatment of cumulative/aggregate risk. The double counting exists because the study of Greer et al. [3] already reflects exposure by all pathways to all goitrogens acting through the sodium-iodide symporter mechanism. The analysis conducted here assumes the exposures to other compounds acting through this mechanism are the same as in the general US population because there was no control on these exposures in the original study.

- Reduction of iodide uptake into the thyroid produces the "downstream" (adverse) effects only at significant levels of decrease, estimated by the US National Research Council [11] to be above 70\%; again, this indicates that the mere presence of inhibition of iodide uptake to the thyroid as a basis for a NOEL, and then treating it as if it were a NOAEL, already includes a margin of safety. By contrast, FAO/WHO/JEFCA [12] set the threshold value for inhibition at 50\%, and California OEHHA set it at 5\% (see www.oehha.ca.gov/water/phg/pdf/PerchloratePHGFeb2015.pdf).

- Control of perchlorate in either water or food should be seen within the context of aggregate and cumulative risk assessment, and a decision taken as to whether control of perchlorate in water is either the most effective (in the sense of protecting public health) or cost effective (in the sense of wisest expenditure of regulatory resources) means of protecting the public against cumulative/aggregate risks from compounds acting by this mechanism.

Insight into the path forward to establishing a regulatory limit on perchlorate under the traditional regulatory assessment approach can be gained from the National Research Council [13] report. That study produced a NOEL of $0.007 \mathrm{mg} / \mathrm{kg}$-day based on the study of Greer et al. [3]. The NRC further recommended a total uncertainty factor of 10 for intraspecies extrapolation (the data were from humans generally, not from pregnant women and/or their fetuses, who might represent the sensitive subpopulation), resulting in a suggested RfD of:

$$
\mathrm{RfD}=0.007 / 10=0.0007 \mathrm{mg} / \mathrm{kg} \text {-day or } 0.7 \mu \mathrm{g} / \mathrm{kg} \text {-day }
$$

This RfD value would, for the case where populations are exposed solely to perchlorate as the inhibitor of iodide uptake, yield a lower bound on the regulatory limit (Reference Concentration or RfC in US EPA regulatory terminology) of $18 \mu \mathrm{g} / \mathrm{L}$, assuming $2 \mathrm{~L} /$ day consumption of water by a woman weighing $50 \mathrm{~kg}$ (chosen here as a health conservative assumption as it is in the lower $25 \%$ of body weights). This calculation uses the upper bound estimate of the ratio of water intake rate per unit body weight. The value is $24.5 \mu \mathrm{g} / \mathrm{L}$ if $70 \mathrm{~kg}$ body weight is used instead. The value of $18 \mu \mathrm{g} / \mathrm{L}$ is retained in the following discussion.

However, the above discussion fails to reflect the issue of cumulative exposure to goitrogens acting by the mechanism considered in the present paper in interpreting the study of Greer et al. [3]. Four alternative approaches to establishing exposure limits on perchlorate are discussed in Section 4, each reflecting different treatments of cumulative/aggregate risk. For each of these, a description is given of the approach and results provided for both perchlorate alone and for PEC.

\section{Four Approaches to Regulatory Control of Risks from Perchlorate and Goitrogens}

The following discussion is rooted in Equation (2). Expanding Equation (2) to be more explicit:

$$
\mathrm{HI}=(\text { ADRIf, } \mathrm{p}+\text { ADRIf, np + ADRIw, } \mathrm{p}+\text { ADRIw, np)/RfD }
$$

where ADRIf,p is the ADRI of perchlorate (p) from food (f); ADRIf, np is the ADRI of non-perchlorate compounds (np) from food acting through the sodium-iodide symporter mechanism to inhibit iodide uptake as measured in the study of Greer et al. [3]; ADRIw, p is the ADRI of perchlorate (p) from water (w); and ADRIw, $\mathrm{np}$ is the ADRI of non-perchlorate compounds (np) from water, again acting through the sodium-iodide symporter mechanism. The value of RfD is identical for the four components, albeit calculated differently for the four approaches summarised below. This requires calculating the ADRI values using PEC rather than the direct mass concentration in the environmental media.

For those PEC values, the summary of results by Tonacchera et al. [14] is used firstly based on four studies (cited in their paper), in which they find ratios of perchlorate: thiocyanate: nitrate of 1:20:240, 1:10:300, $1: 20: 400$ and 1:20:500, each of which is based on circulating serum molar concentration [15] [16]. Converting to effectiveness of inhibition per unit serum concentration, they recommend ratios of 1:8.8:150. This means a direct mass concentration of 1 unit of perchlorate is equivalent to 8.8 units of thiocyanate and 150 units of nitrate on the basis of equivalent serum concentration. When circulation half-lives in serum are included, the result 
is ratios of 1:0.5:240 on the basis of ingested quantity (the unit of interest here). The two values for PEC calculations above (1:8.8:150 and 1:0.5:240) are used here as upper and lower bounding estimates for the calculations that follow; when detailed PBPK and BBDR models are available for the three compounds considered here, these PEC values are likely to change.

For typical background estimates of the various components to Equation (2) revised, the results are as follows based on a central tendency US diet; the choice to use a US diet is because the study population of Greer et al. [3] is represented by this diet, and hence it is this diet that is relevant in calculating non-perchlorate and nonwater exposures.

- For perchlorate in water, the ADRI is $0.004 \mu \mathrm{g} / \mathrm{kg}$-day [17];

- For perchlorate in food, the ADRI is $0.1 \mu \mathrm{g} / \mathrm{kg}$-day [18];

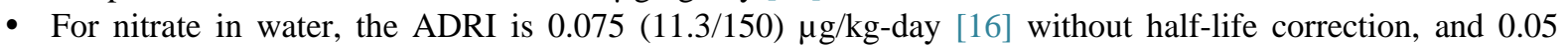

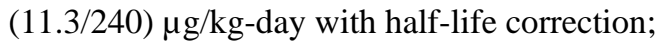

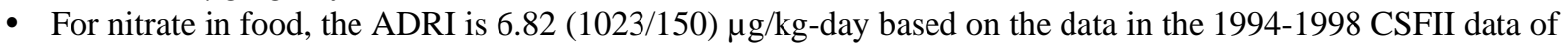
the USDA available in 2010;

- For endogenous (END) nitrate production, the estimate is $45 \%$ of total nitrate exposure (END + NONEND) is via this component [11], and therefore the endogenous contribution would be $(0.075+6.82) * 0.82=5.65$ $\mu \mathrm{g} / \mathrm{kg}$-day; in this calculation, the equality $0.45=\mathrm{END} /(\mathrm{END}+\mathrm{NONEND})$ is solved, so END $=(0.45 / 0.55) \times$ NONEND $=0.82 \times$ NONEND;

- For thiocyanates in food (using the USDA CFSII data), the ADRI is $0.86(7.5 / 8.8) \mu \mathrm{g} / \mathrm{kg}$-day or $15 \mu \mathrm{g} / \mathrm{kg}$ day (with half-life correction). Intakes from water are negligible. The NHANES urinary data suggest this to be an underestimate of thiocyanate exposure in the bloodstream, probably due to endogenous production.

Again, the values above are in units of PEC. To summarize, background ADRI values (in PEC units) corresponding to the components of Equation (2) (revised) are:

- Perchlorate in water: $0.004 \mu \mathrm{g} / \mathrm{kg}$-day;

- Total goitrogens (acting through the sodium-iodide symporter mechanism) in water: $0.075+0.004=0.079$ $\mu \mathrm{g} / \mathrm{kg}$-day without half-life correction, and $0.05+0.004=0.054 \mu \mathrm{g} / \mathrm{kg}$-day with half-life correction;

- Total goitrogens (acting through the sodium-iodide symporter mechanism) in food: $0.1+6.82+5.65+0.86$ $=13.42 \mu \mathrm{g} / \mathrm{kg}$-day without half-life correction, and $0.1+4.2+3.5+15=22.8 \mu \mathrm{g} / \mathrm{kg}$-day with half-life correction.

\subsection{Approach 1}

The approach here is to use the study of Greer et al. [3] in the procedure typically followed in regulatory decisions in establishing exposure limits by a single pathway to a single contaminant. The NOEL is then 0.007 $\mathrm{mg} / \mathrm{kg}$-day. The RfD is $0.007 / 10=0.0007 \mathrm{mg} / \mathrm{kg}$-day or $0.7 \mu \mathrm{g} / \mathrm{kg}$-day, with the Uncertainty Factor of 10 accounting for intraspecies variability to reflect a concern for pregnant women and their fetuses, but with no need for further uncertainty factors since this RfD already contains a margin of safety due to the use of a precursor to adverse effect rather than using an adverse effect itself. No RSC value should be applied both because it falls below the $10 \%$ - $20 \%$ guideline (for example, using average values for water and non-water, this fraction is $0.004 / 0.1004=0.038=3.8 \%$ ) considered by the US EPA as justifiable and because non-water exposures are already present in the Greer et al. [3] study.

Resulting allowed concentration for perchlorate in water: $18 \mu \mathrm{g} / \mathrm{L}$ in water for a water intake rate of $2 \mathrm{~L} /$ day (the regulatory default) and a body weight of $50 \mathrm{~kg}$. This uses the equation Concentration $(\mu \mathrm{g} / \mathrm{L}$ water $)=0.7$ $(\mu \mathrm{g} / \mathrm{kg}$-day $) \times 50(\mathrm{~kg}) / 2(\mathrm{~L}$ water/day $)=18 \mu \mathrm{g} / \mathrm{L}$.

Resulting allowed concentrations for goitrogens (PEC) in water: Approach 1 does not consider total goitrogens in water acting through the sodium-iodide symporter mechanism because it considers only the incremental exposure to perchlorate, without reference to any specific mechanism. The same concentration of $18 \mu \mathrm{g} / \mathrm{L} \mathrm{can}$, however, be used for the sum of all goitrogens (PEC; again, considering only those acting through the sodiumiodide symporter mechanism) in water so long as this intake refers to the increment above the background exposures to these compounds.

\subsection{Approach 2}

The approach here is to use the study of Greer et al. [3] to produce an exposure-response relationship for iodide 
uptake inhibition via the sodium-iodide symporter mechanism, coupled to the current best scientific estimates of the percentage inhibition necessary to produce a down-stream adverse effect (5\% or $50 \%$ as described previously). This is equivalent to Equations $1 \mathrm{~A}-1 \mathrm{D}$ in the paper of Greer et al. [3] (see page 931 of that paper). These equations are valid only for the region of doses in the study ( $0.007 \mathrm{mg} / \mathrm{kg}$-day and above).

$$
\begin{array}{ll}
(\mathrm{RU}) \mathrm{E} 2=(-0.374) \log 10 \mathrm{D}+(0.209) & \text { [Equation 1A in Greer et al.] } \\
(\mathrm{RU} 24) \mathrm{E} 2=(-0.373) \log 10 \mathrm{D}+(0.202) & \text { [Equation 1B in Greer et al.] } \\
(\mathrm{RU}) \mathrm{E} 14=(-0.337) \log 10 \mathrm{D}+(0.229) & \text { [Equation 1C in Greer } \text { et al.] } \\
(\mathrm{RU} 24) \mathrm{E} 14=(-0.359) \log 10 \mathrm{D}+(0.213) & \text { [Equation 1D in Greer et al.] }
\end{array}
$$

where $\mathrm{D}$ is the excess intake of perchlorate during the experiment (i.e., not the total intake of perchlorate or of other compounds included in aggregate and cumulative exposure) in units of ADRI (mg/kg-day); RU8 is the reduction in iodide uptake at 8 hours; RU24 is the reduction in iodide uptake at 24 hours; and E2 and E14 are the two sets of cases.

For Approaches 2 and 4, the estimated exposure-response function (percent inhibition) for iodide uptake at 24 hours following exposure to perchlorate in the study of Greer et al. [3] or other goitrogens acting through the sodium-iodide symporter mechanism is employed. If used for cases of cumulative risk, the value of ADRI must reflect the PEC of each compound relative to perchlorate (hence perchlorate has a PEC value of 1).

From these results, the change in response is zero at doses below approximately $0.01 \mathrm{mg} / \mathrm{kg}$-day, indicating that homeostatic mechanisms are fully operational at these low doses.

Using the Equations for E2 and E14 and averaging over the two sets of cases, the value of ADRI corresponding to a $50 \%$ decline in iodide uptake relative to the Baseline Visit value is $0.16 \mathrm{mg} / \mathrm{kg}$-day (160 $\mu \mathrm{gg} / \mathrm{kg}$-day). With a 10 fold uncertainty factor applied to the increment of dose above background, the resulting RfD for a 50\% decline required to induce the specified levels of iodide uptake inhibition is $0.016 \mathrm{mg} / \mathrm{kg}$-day (or $16 \mu \mathrm{g} / \mathrm{kg}$-day). Note that the resulting RfC is a factor of 23 (16/0.7) above that from Approach 1. The value of ADRI corresponding to a $5 \%$ decline in iodide uptake relative to the Baseline Visit value is approximately $0.015 \mathrm{mg} / \mathrm{kg}$-day (15 $\mu \mathrm{g} / \mathrm{kg}$-day). With a 10 fold uncertainty factor applied to the increment of dose above background, the resulting RfD required to induce the specified levels of iodide uptake inhibition is $0.0015 \mathrm{mg} / \mathrm{kg}$-day (or 1.5 $\mu \mathrm{g} / \mathrm{kg}$-day).

Note that in this Approach, the measured effect (iodide uptake inhibition) remains a precursor to adverse effects rather than an adverse effect itself, but the level of inhibition is high enough to correlate well with the eventual down-stream production of adverse effects.

Resulting allowed concentration for perchlorate in water (50\% decline in iodide uptake required): 400 $\mu \mathrm{g} / \mathrm{L}$ for a water intake rate of $2 \mathrm{~L} /$ day (the regulatory default) and a body weight of $50 \mathrm{~kg}$ using the same calculation as in Approach 1 but with the higher RfD. This uses the equation Concentration $(\mu \mathrm{g} / \mathrm{L}$ water) $=16$ $(\mu \mathrm{g} / \mathrm{kg}$-day $) \times 50(\mathrm{~kg}) / 2(\mathrm{~L}$ water $/$ day $)=400 \mu \mathrm{g} / \mathrm{L}$.

Resulting allowed concentration for perchlorate in water (5\% decline in iodide uptake required): $38 \mu \mathrm{g} / \mathrm{L}$ for a water intake rate of $2 \mathrm{~L} /$ day (the regulatory default) and a body weight of $50 \mathrm{~kg}$ using the same calculation as in Approach 1. This uses the equation Concentration $(\mu \mathrm{g} / \mathrm{L}$ water $)=1.5(\mu \mathrm{g} / \mathrm{kg}$-day $) \times 50(\mathrm{~kg}) / 2(\mathrm{~L}$ water $/$ day $)$ $=38 \mu \mathrm{g} / \mathrm{L}$.

Resulting allowed concentration for goitrogens (PEC) in water: The same concentrations of $400 \mu \mathrm{g} / \mathrm{L}$ (50\% inhibition) or $38 \mu \mathrm{g} / \mathrm{L}$ (5\% inhibition) can be used for the sum of all goitrogens (PEC) acting through the sodium-iodide symporter mechanism in water so long as this intake refers to the increment above the background exposures.

\subsection{Approach 3}

The approach here is to use the Greer et al. [3] NOEL of $0.007 \mathrm{mg} / \mathrm{kg}$-day, but recognize the contribution of the other compounds (nitrates and thiocyantes here) to the total intake of compounds acting through the sodium-iodide symporter mechanism in that study. In other words, the NOEL from that study is not a NOEL associated solely with perchlorate intakes during the study, but a NOEL reflecting the combined effect of all compounds with the same mechanism of action present in the diet of the study subjects. The approach is to determine the actual intake rate of perchlorate and the other two compounds from all routes of exposure for the pop- 
ulation of Greer et al. [3] with application of a PEC factor to each of the compounds as was specified in Equation 2. The x-axis on the exposure-response relationship is adjusted accordingly. This new graph is then used to establish the NOEL reflecting cumulative and aggregate risk.

Charnley [15] reviewed both the exposure and effects data through 2008. She concludes: "Based on data from 27 foods, the US FDA has made a preliminary estimate of average daily perchlorate intake in the US of 0.053 $\mu \mathrm{g} / \mathrm{kg} /$ day [19], similar to that estimated on the basis of urinary perchlorate measurements, $0.066 \mu \mathrm{g} / \mathrm{kg} / \mathrm{day}$ [17]”. Intakes of perchlorate through the diet in the population of Greer et al. [3] are evidently significantly smaller than the perchlorate consumed at the NOEL ( $7 \mu \mathrm{g} / \mathrm{kg}$-day). As shown below, however, this preliminary estimate is significantly lower than what one obtains when more complete data (provided below) are considered.

In addition, the concern for goitrogens acting through the sodium-iodide symporter mechanism is not dominated by perchlorate. Of direct interest here is the daily intake rate of other compounds such as those listed at the beginning of Section 3 above. The calculations here are based on the results of Tonacchera et al. [13] using PEC ratios of 1:15:240 or 1:8.8:150 for ClO4-:SCN-:NO3- on the molar- and weight-based ratios respectively. Again, these ratios are 1:0.5:240 on the basis of ingested quantity when a serum half-life correction is applied.

As shown earlier, total background ADRI (using PEC) for perchlorate, nitrates and thiocyanates is approximately $0.004+0.075+13.42=13.5 \mu \mathrm{g} / \mathrm{kg}$-day without serum half-life corrections or $0.004+0.05+22.8=$ $22.9 \mu \mathrm{g} / \mathrm{kg}$-day if half-life corrections are included. This in turn suggests (even if only these two additional compounds are considered) that the NOEL of $0.007 \mathrm{mg} / \mathrm{kg}$-day from the Greer et al. [3] study is associated with a total PEC intake rate of $13.5 \mu \mathrm{g} / \mathrm{kg}$-day (without half-life) or $22.9 \mu \mathrm{g} / \mathrm{kg}$-day (with half-life).

Resulting allowed concentration for perchlorate in water: $338 \mu \mathrm{g} / \mathrm{L}$ (without serum half-life correction) or $573 \mu \mathrm{g} / \mathrm{L}$ (with serum half-life correction) for a water intake rate of $2 \mathrm{~L} /$ day (the regulatory default) and a body weight of $50 \mathrm{~kg}$ using the same calculation as in Approach 1 but with the higher RfD. These values use the equation Concentration $(\mu \mathrm{g} / \mathrm{L}$ water $)=13.5(\mu \mathrm{g} / \mathrm{kg}$-day $) \times 50(\mathrm{~kg}) / 2(\mathrm{~L} /$ day $)=338 \mu \mathrm{g} / \mathrm{L}$ (without serum half-life correction) or $22.9 \mu \mathrm{g} / \mathrm{kg}$-day $\times 50(\mathrm{~kg}) / 2(\mathrm{~L} /$ day $)=573 \mu \mathrm{g} / \mathrm{L}$ (with serum half-life correction). This calculation presumes perchlorate is the sole contributor to the cumulative risk from goitrogens acting through the sodium-iodide symporter mechanism.

Resulting allowed concentration for goitrogens (PEC) in water: The same concentration of $338 \mu \mathrm{g} / \mathrm{L}$ (without serum half-life correction) or $573 \mu \mathrm{g} / \mathrm{L}$ (with serum half-life correction) can be used for the sum of all compounds (PEC) acting through the sodium-iodide symporter mechanism in water.

\subsection{Approach 4}

The approach here is to use the study of Greer et al. [3] to produce an exposure-response relationship for iodide uptake inhibition through the sodium-iodide symporter mechanism, coupled to a range of estimates of the percentage inhibition necessary to produce a down-stream adverse effect. As in Approach 2, a 50\% inhibition is associated with an ADRI of $16 \mu \mathrm{g} / \mathrm{kg}$-day (administered intake from water in the Greer et al. [3] study) + 13.5 $\mu \mathrm{g} / \mathrm{kg}$-day (background) $=29.5 \mu \mathrm{g} / \mathrm{kg}$-day (without serum half-life correction), or $16 \mu \mathrm{g} / \mathrm{kg}$-day (administered intake from water in the study of Greer et al. [3]) $+22.9 \mu \mathrm{g} / \mathrm{kg}$-day (background) $=38.9 \mu \mathrm{g} / \mathrm{kg}$-day (with serum half-life correction). And again as in Approach 2, a 5\% inhibition is associated with an ADRI of $1.5 \mu \mathrm{g} / \mathrm{kg}$-day (administered intake from water in the Greer et al. [3] study) $+13.5 \mu \mathrm{g} / \mathrm{kg}$-day (background) $=15 \mu \mathrm{g} / \mathrm{kg}$-day (without serum half-life correction), or $1.5 \mu \mathrm{g} / \mathrm{kg}$-day (administered intake from water in the Greer et al. [3] study) $+22.9 \mu \mathrm{g} / \mathrm{kg}$-day (background) $=24.4 \mu \mathrm{g} / \mathrm{kg}$-day (with serum half-life correction).

Resulting allowed concentration for perchlorate in water ( $50 \%$ decline in iodide uptake required): 737 $\mu \mathrm{g} / \mathrm{L}$ for a water intake rate of $2 \mathrm{~L} /$ day (the regulatory default) and a body weight of $50 \mathrm{~kg}$ using the same calculation as in Approach 1 but with the higher RfD (without serum half-life correction) or $973 \mu \mathrm{g} / \mathrm{L}$ (with serum half-life correction). This uses the equation Concentration $(\mu \mathrm{g} / \mathrm{L}$ water $)=29.5(\mu \mathrm{g} / \mathrm{kg}$-day) $\times 50(\mathrm{~kg}) / 2(\mathrm{~L}$ water/day) $=737 \mu \mathrm{g} / \mathrm{L}$ (without serum half-life correction) or $38.9(\mu \mathrm{g} / \mathrm{kg}$-day $) \times 50(\mathrm{~kg}) / 2(\mathrm{~L} /$ day $)=973 \mu \mathrm{g} / \mathrm{L}$ (with serum half-life correction). This calculation presumes perchlorate is the sole contributor to the cumulative risk from goitrogens acting through the sodium-iodide symporter mechanism.

Resulting allowed concentration for perchlorate in water ( $5 \%$ decline in iodide uptake required): $375 \mu \mathrm{g} / \mathrm{L}$ for a water intake rate of $2 \mathrm{~L} /$ day (the regulatory default) and a body weight of $50 \mathrm{~kg}$ using the same calculation as in Approach 1 but with the higher RfD (with no serum half-life correction), or $635 \mu \mathrm{g} / \mathrm{L}$ (with no serum half-life correction). This uses the equation Concentration $(\mu \mathrm{g} / \mathrm{L}$ water $)=15(\mu \mathrm{g} / \mathrm{kg}$-day $) \times 50(\mathrm{~kg}) / 2(\mathrm{~L}$ wa- 
ter/day) $=375 \mu \mathrm{g} / \mathrm{L}$ (without serum half-life correction) or $25.4(\mu \mathrm{g} / \mathrm{kg}$-day $) \times 50(\mathrm{~kg}) / 2(\mathrm{~L} /$ day $)=635 \mu \mathrm{g} / \mathrm{L}$ (with serum half-life correction). This calculation presumes perchlorate is the sole contributor to the cumulative risk from goitrogens acting through the sodium-iodide symporter mechanism.

Resulting allowed concentration for goitrogens (PEC) in water: The concentration of $737 \mu \mathrm{g} / \mathrm{L}$ (without serum half-life correction) or $973 \mu \mathrm{g} / \mathrm{L}$ (with serum half-life correction) can be used for the sum of all goitrogens (PEC) in water for an assumed inhibition threshold of $50 \%$. The concentration of $375 \mu \mathrm{g} / \mathrm{L}$ (without serum half-life correction) or $635 \mu \mathrm{g} / \mathrm{L}$ (with serum half-life correction) can be used for the sum of all goitrogens (PEC) in water for an assumed inhibition threshold of $5 \%$.

\section{Conclusions}

The analyses of Section 4 suggest that regulatory limits on perchlorate exposures in water are protective of public health at somewhere between $18 \mu \mathrm{g} / \mathrm{L}$ and $973 \mu \mathrm{g} / \mathrm{L}$, with the value dependent on the approach taken to incorporate cumulative risk into regulatory risk assessment, on the inclusion or not of serum half-life correction, and the non-perchlorate exposures to compounds acting by this mechanism. The four approaches considered here yield the following estimates of the safe levels in water of perchlorate (when perchlorate in water is the sole intake of goitrogens) or total goitrogens (PEC; where there are multiple goitrogens present in the water but again where water is the sole route of exposure):

- Approach 1: $18 \mu \mathrm{g} / \mathrm{L}$;

- Approach 2: $400 \mu \mathrm{g} / \mathrm{L}$ (50\% required inhibition) or $38 \mu \mathrm{g} / \mathrm{L}$ (5\% required inhibition);

- Approach 3: $338 \mu \mathrm{g} / \mathrm{L}$ (without serum half-life correction) or $573 \mu \mathrm{g} / \mathrm{L}$ (with serum half-life correction);

- Approach 4: $737 \mu \mathrm{g} / \mathrm{L}$ (without serum half-life correction) or $973 \mu \mathrm{g} / \mathrm{L}$ (with serum half-life correction) for $50 \%$ required inhibition; $375 \mu \mathrm{g} / \mathrm{L}$ (without half-life) or $735 \mu \mathrm{g} / \mathrm{L}$ (with half-life) for $5 \%$ required inhibition.

Finally, it is noted that the science of both effects of perchlorate and goitrogen is expanding rapidly. The current paper has considered only assessments performed within the traditional regulatory framework rooted in NOELs, LOELs, etc. There are significant advances in both the PBPK and BBDR models of perchlorate [20] [21] which will move the regulatory community towards a more biologically based approach to establishing benchmark doses rather than developing NOELs or LOELs. This includes better understanding of the role of endogenously produced goitrogens, such as nitrates and thiocyanates, although the models are not yet well developed for application to cumulative risk assessment.

When these scientific advances are reflected in analyses, the establishment of a benchmark dose associated with each goitrogen and the interactions between the goitrogens reflected in calculation of PEC will change. As mentioned briefly earlier, this increased understanding may include secondary modes or mechanisms of action by at least perchlorate and quantified contributions to levels of inhibition by routes such as smoking [22] [23].

\section{References}

[1] Crawford-Brown, D. and Crawford-Brown, S. (2012) Cumulative Risk Assessment Framework for Waterborne Contaminants. Journal of Environmental Protection, 3, 400-413. http://dx.doi.org/10.4236/jep.2012.35050

[2] Sexton, K. and Linder, S. (2010) The Role of Cumulative Risk Assessment in Decisions about Environmental Justice. International Journal of Environmental Research and Public Health, 7, 4037-4049. http://dx.doi.org/10.3390/ijerph7114037

[3] Greer, M., Goodman, G., Pleus, R. and Greer, S. (2002) Health Effects Assessment for Environmental Perchlorate Contamination: The Dose-response for Inhibition of Thyroidal Radioiodide Uptake in Humans. Environmental Health Perspectives, 110, 927-937. http://dx.doi.org/10.1289/ehp.02110927

[4] Sand, P. (2000) The Precautionary Principle: A European Perspective. Human and Ecological Risk Assessment, 6, 445448. http://dx.doi.org/10.1080/10807030091124563

[5] Wiener, J. and Rogers, M. (2002) Comparing Precaution in the United States and Europe. Journal of Risk Research, 5, 317-349. http://dx.doi.org/10.1080/13669870210153684

[6] EPA (2012) Life Stage Considerations and Interpretation of Recent Epidemiological Evidence to Develop a Maximum Contaminant Level Goal for Perchlorate. USEPA White Paper, Health and Ecological Criteria Division, Office of Science and Technology, Office of Water, Washington DC.

[7] Crofton, K. (2008) Thyroid Disrupting Chemicals: Mechanisms and Mixtures. International Journal of Andrology, 31, 209-223. http://dx.doi.org/10.1111/j.1365-2605.2007.00857.x 
[8] McLanahan, E., Andersen, M., Campbell, J. and Fisher, J. (2009) Competitive Inhibition of Thyroidal Uptake of Dietary Iodide by Perchlorate Does Not Account for Perturbations in Rat Serum Total T4 and TSH. Environmental Health Perspectives, 117, 731-738. http://dx.doi.org/10.1289/ehp.0800111

[9] Engel, A. and Lamm, S. (2003) Chapter 15: Goitrogens in the Environment. In: Braverman, L.E., Ed., Diseases of the Thyroid, 2nd Edition, Humana Press, New York.

[10] Weller, E., Long, N., Smith, A., Williams, P., Ravi, S., Gill, J., et al. (1999) Dose-Rate Effects of Ethylene Oxide Exposure on Developmental Toxicity. Toxicological Sciences, 50, 259-270. http://dx.doi.org/10.1093/toxsci/50.2.259

[11] National Research Council (1995) Nitrate and Nitrite in Drinking Water, Subcommittee on Nitrate and Nitrite in Drinking Water. National Academy Press, Washington DC, 38.

[12] FAO/WHO (2011) Evaluations of the Joint FAO/WHO Expert Committee on Food Additives (JECFA). Perchlorate. http://apps.who.int/food-additives-contaminants-jecfa-database/chemical.aspx?chemID=5885

[13] National Research Council (2005) Health Implications of Perchlorate Exposure. National Academy Press, Washington DC.

[14] Tonacchera, M., Pinchera, A., Dimida, A., Ferrarini, E., Agretti, P., Vitti, P., Santini, F., Crump, K. and Gibbs, J. (2004) Relative Potencies and Additivity of Perchlorate, Tthiocyanate, Nitrate, and Iodide on the Inhibition of Radioactive Iodide Uptake by the Human Sodium Iodide Symporter. Thyroid, 14, 1012-1019. http://dx.doi.org/10.1089/thy.2004.14.1012

[15] Charnley, G. (2008) Perchlorate: Overview of Risks and Regulation. Food and Chemical Toxicology, 46, $2307-2315$. http://dx.doi.org/10.1016/j.fct.2008.03.006

[16] De Groef, B., Decallonne, B., Van der Geyten, S., Darras, V. and Bouillon, R. (2006) Perchlorate versus Other Environmental Sodium/iodide Symporter Inhibitors: Potential Thyroid-Related Health Effects. European Journal of Endocrinology, 155, 17-25. http://dx.doi.org/10.1530/eje.1.02190

[17] Blount, B., Valentin-Blasini, L., Osterloh, J., Mauldin, J. and Pirkle, J. (2006) Perchlorate Exposure of the US Population, 2001-2002. Journal of Exposure Science and Environmental Epidemiology, 17, 400-407. http://dx.doi.org/10.1038/sj.jes.7500535

[18] Murray, C., Egan, S., Kim, H. and Bolger, P. (2008) US Food and Drug Administration’s Total Diet Study: Dietary Intake of Perchlorate and Iodide. Journal of Exposure Science and Environmental Epidemiology, 18, 571-580. http://dx.doi.org/10.1038/sj.jes.7500648

[19] US Food and Drug Administration (US FDA) (2007) Preliminary Estimation of Perchlorate Dietary Exposure Based on FDA 2004/2005 Exploratory Data. Center for Food Safety and Applied Nutrition. www.fda.gov/Food/FoodborneIllnessContaminants/ChemicalContaminants/ucm077653.htm

[20] Crump, K. and Gibbs, J. (2005) Benchmark Calculations for Perchlorate from Three Human Cohorts. Environmental Health Perspectives, 113, 1001-1008. http://dx.doi.org/10.1289/ehp.7814

[21] EPA (2009) Inhibition of the Sodium-Iodide Symporter by Perchlorate: An Evaluation of Life Stage Sensitivity Using Physiologically Based Pharmacokinetic (PBPK) Modeling. EPA/600/R-08/106A, Washington DC.

[22] Laurberg, P., Nohr, S., Pedersen, K. and Fuglsang, E. (2004) Iodine Nutrition in Breast-Fed Infants Is Impaired by Maternal Smoking. Journal of Clinical Endocrinology and Metabolism, 89, 181-187. http://dx.doi.org/10.1210/jc.2003-030829

[23] Steinmaus, C. Miller, M. and Howd, R. (2007) Impact of Smoking and Thiocyanate on Perchlorate and Thyroid Hormone Associations in the 2001-2002 National health and nutrition examination survey. Environmental Health Perspectives, 115, 1333-1338. http://dx.doi.org/10.1289/ehp.10300 